\title{
Calcium hydroxide silylation reaction with trimethylchlorosilane
}

\author{
Anatoliy A. Novoselnov ${ }^{1, *}$, and Yuliya $V$. Ustinova ${ }^{1}$ \\ ${ }^{1}$ Moscow State University of Civil Engineering, 26, Yaroslavskoye Shosse, 129337 Moscow, Russia
}

\begin{abstract}
The silylation reaction of a calcium hydroxide with a trimethylchlorosilane is studied as a silylation model by the gas-liquid chromatography. The silylation process is divided into three stages. A material balance of these stages is calculated. The schemes of the reactions at each stage of the process are proposed. The modified calcium hydroxide obtained at three repetitive stages of the silylation reaction has been investigated by the x-ray phase analysis, IR spectroscopy, thermal analysis, electron microscopy in a combination with the elemental analysis. It has been determined that at the first stage of the interaction the processes of the trimethylchlorosilane hydrolysis and of the hydrolysis products condensation dominate, and at the same time an adsorption process of the trimethylchlorosilane and its derivatives starts. Further, the hydrolysis of the trimethylchlorosilane by the «new» portions of a water formed in the reaction of a calcium hydroxide with a hydrogen chloride takes place, simultaneously the secondary reactions of the Si-O-Ca - ties' formation and cleavage occur including as a silylation-desilylation dynamic equilibrium process.
\end{abstract}

An interest to the silylation of the mineral components included in the building materials is caused by the fact that it is one of the most of effective chemical methods of the increase of exploitation characteristics of building materials and products and above all hydrophobicity [1]. It is believed that the effectiveness of this chemical interaction is determined primarily by the chemical nature, both the construction material and the silylating agent.

The researches of the silylation reaction of the various building minerals with the organo-silicon compounds (OSC) have been conducted for several years $[2,3,4,5,6,7]$.

An interaction between the different organosilanes with the functional groups at the silicon atom $\left(\mathrm{Si}\right.$ ) of the general formula $\mathrm{R}_{\mathrm{n}} \mathrm{SiX}_{4-\mathrm{n}}$ (wherein: $\mathrm{R}=\mathrm{CH}_{3}, \mathrm{C}_{2} \mathrm{H}_{2}, \mathrm{C}_{6} \mathrm{H}_{5} ; \mathrm{n}=1-3 ; \mathrm{X}=$ $\mathrm{Cl}$, OR; $\left.\mathrm{R}=\mathrm{CH}_{3}, \mathrm{C}_{2} \mathrm{H}_{2}\right)$ and $\mathrm{CaO},\left(3 \mathrm{CaO} \cdot \mathrm{SiO}_{2}\right)_{\mathrm{n}}, \mathrm{CaCO}_{3}, \mathrm{CaSO}_{4}$ and Portland cement, as well as their derivatives of hydrated minerals, has been studied in details. And it will be the subject of our further reports.

Portland cement is a multi-compound system. The main mineral of the Portland cement clinker is alite $\left(3 \mathrm{CaO} \cdot \mathrm{SiO}_{2}\right)_{\mathrm{n}}$. The most active part of the hydrated $\left(3 \mathrm{CaO} \cdot \mathrm{SiO}_{2}\right)_{\mathrm{n}}$ is $\mathrm{Ca}(\mathrm{OH})_{2}$, which is the main product of its hydrolysis:

* Corresponding author: anovo@inbox.ru 


$$
\left(3 \mathrm{CaO} \cdot \mathrm{SiO}_{2}\right)_{\mathrm{n}}+2 \mathrm{n} \mathrm{H}_{2} \mathrm{O} \rightarrow \mathrm{n} \mathrm{Ca}(\mathrm{OH})_{2}+\left(2 \mathrm{CaO} \cdot \mathrm{SiO}_{2} \cdot \mathrm{H}_{2} \mathrm{O}\right)_{\mathrm{n}}
$$

Thus the main researches have been aimed to the studies of the silylation reaction of the calcium hydroxide.

An investigation of the silylation reaction of the calcium hydroxide with the $\mathrm{Me}_{3} \mathrm{Si}-\mathrm{Cl}$ trimethylchlorosilane (TMCS) has been carried out by the gas-liquid chromatography (GLC) method. The TMCS's concentration change in the reaction mixture has been observed. The silylation reaction has been carried out in a heterogeneous medium, with a molar ratio of mineral : $\mathrm{OSC}=10: 1$, and stirring the reaction mixture at $18-20{ }^{\circ} \mathrm{C}$ for 300 minutes (hereinafter up to 7 days); inert solvent is nonane; internal standard is toluene [8]. The way of the reaction has been estimated by changes in the TMCS conversion in relation to its internal standard toluene. At the same time, we have conducted a control experiment without minerals. Under carrying out a control experiment any change in a TMCS's concentration in the reaction mixture hasn't been observed.

Trimethylchlorosilane $\mathrm{Me}_{3} \mathrm{Si}-\mathrm{Cl}$ is one of the first organo-silicon compounds, which has been applied for the building materials modification [1]. The TMCS conversion change and the extraction of the hexamethyldisiloxane $\mathrm{Me}_{3} \mathrm{Si}-\mathrm{O}-\mathrm{SiMe}_{3}$ (HMDS), the main product of its hydrolysis, make it possible to calculate the material balance of the silylation reaction. The HMDS formation occurs under the hydrolysis of the TMCS with a water, which can be found in the calcium hydroxide, according to the following schemes:

$$
\begin{gathered}
\mathrm{Me}_{3} \mathrm{Si}-\mathrm{Cl}+\mathrm{HOH} \rightarrow \mathrm{Me}_{3} \mathrm{Si}-\mathrm{OH}+\mathrm{HCl} \\
\mathrm{Me}_{3} \mathrm{Si}-\mathrm{OH}+\mathrm{HO}-\mathrm{SiMe}_{3} \rightarrow \mathrm{Me}_{3} \mathrm{Si}-\mathrm{O}-\mathrm{SiMe}_{3}+\mathrm{HOH} \\
\mathrm{Me}_{3} \mathrm{Si}-\mathrm{Cl}+\mathrm{HO}-\mathrm{SiMe}_{3} \rightarrow \mathrm{Me}_{3} \mathrm{Si}_{-} \mathrm{O}-\mathrm{SiMe}_{3}+\mathrm{HCl}
\end{gathered}
$$

Hexamethyldisiloxane is a compound with a hydrolytically stable bond, however, it has been impossible to exclude its interaction with a calcium hydroxide under the scheme:

$$
\mathrm{Me}_{3} \mathrm{Si}-\mathrm{O}-\mathrm{SiMe}_{3}+\mathrm{Ca}(\mathrm{OH})_{2} \rightarrow \mathrm{Me}_{3} \mathrm{SiOH}+\mathrm{Me}_{3} \mathrm{Si}-\mathrm{O}-\mathrm{Ca}-\mathrm{OH}
$$

HMDS's reactivity to the $\mathrm{Ca}(\mathrm{OH})_{2}$ has been examined by GLC method. At carrying out of the reaction (in a nonane, for 14 days) any change in the HMDS's concentration in the reaction mixture hasn't been observed.

The data of the X-ray diffraction, IR spectrum and thermal analysis of the modified sample are virtually indistinguishable from the test results of the initial calcium hydroxide. Even under the calcium hydroxide reflux with a fivefold molar excess of the HMDS in a nonane for 24 hours and at the reflux with a fivefold molar excess of the HMDS in an acetonitrile for 24 hours, any characteristic of the reaction according to the scheme 5 hasn't been found.

A Fig. 1 shows a dependence of the TMCS conversion from the time of the silylation (up to 300 minutes).

The dependence of the TMCS conversion from the time of the interaction with the calcium hydroxide (Fig. 1) shows that its conversion increases to $22 \%$ for 300 minutes of silylation.

An analysis of the data represented by the Fig.1 including a material balance of the products of the reaction mixture brings to the following conclusion: there are three periods 
observed in the silylation process: I - up to 60 minutes; II - from 60 to 180 minutes and III - from 180 to 300 minutes.

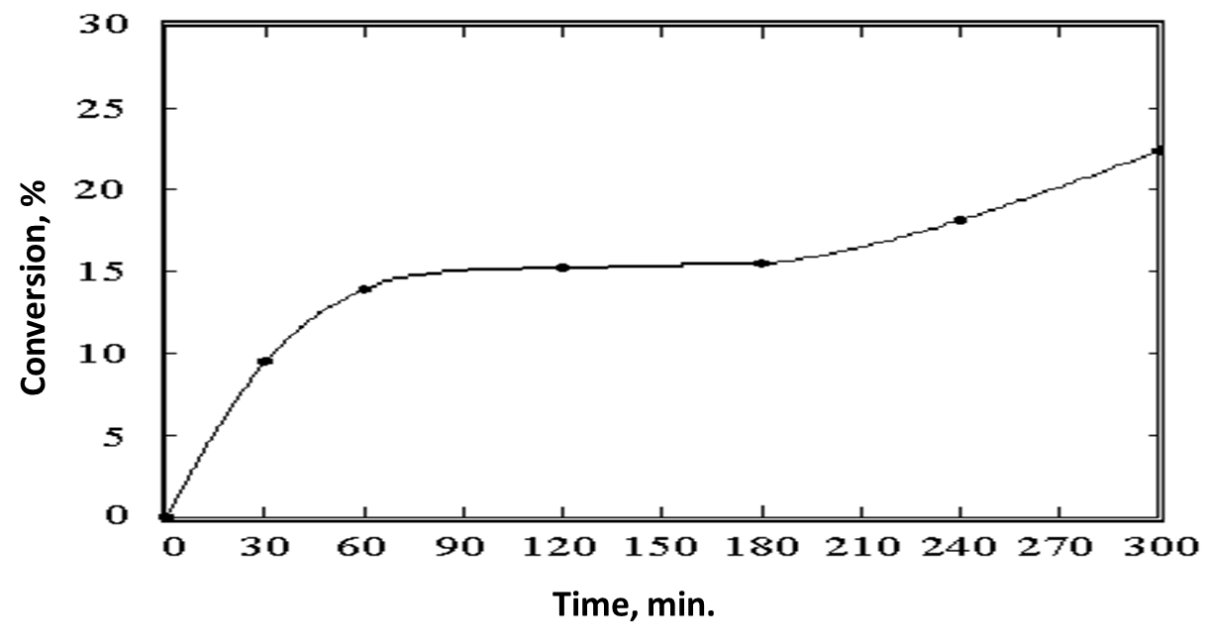

Fig. 1. A dependence of the TMCS conversion on the interaction time with $\mathrm{Ca}(\mathrm{OH})_{2}$

The data shown above approve that an interaction of a TMCS with a calcium hydroxide is very complex and do not much correspond to the data given in [9] and represented for the general estimation of the functional organosilanes with the minerals, where three stages of the process with the different rates can be observed:

1. Stage of the «relatively rapid establishment of the equilibrium sorption».

2. Stage of the «sorption equilibrium», characterized by a slight change in the organosilane's concentration in the reaction mixture.

3. Stage of the «condensation», leading to the formation of the organopolysiloxane coating with its fixing on a mineral's surface.

To evaluate a role of a water adsorbed on a calcium hydroxide's surface, at the first stage of a process a silylation of the mineral with the different preparation degrees has been carried out: a) initial calcium hydroxide; b) calcium hydroxide heated for 3 hours under 140 ${ }^{\circ} \mathrm{C}$; c) calcium hydroxide heated for 12 hours under $250{ }^{\circ} \mathrm{C}$ and vacuum of $0.5 \mathrm{~mm}$. $\mathrm{Hg}$.

It has been discovered that after 30 minutes, the proportion of the reacted calcium hydroxide, transformed to the HMDS is: $95 \%$ for (a), $86 \%$ for (b), and $14 \%$ for (c). Accordingly, the absorption of the TMCS (weight percentage of reacted) account for: (a) $5 \%$, (b) $-14 \%$, and (c) $-86 \%$. Thus, in a first stage (up to 60 minutes) the TMCS's interaction with a calcium hydroxide can be explained mainly by the hydrolysis of the TMCS by the adsorbed water.

The first period of the calcium hydroxide silylation with a trimethylchlorosilane (up to 60 minutes) is a period, which possibly corresponds to the stage of the «equilibrium sorption establishment». At the end of this period a trimethylchlorosilane's conversion rises to $14 \%$.

Table 1. A material balance of the first period of the silylation

\begin{tabular}{|c|c|c|c|}
\hline Periods, min. & $\mathbf{0 - 3 0}$ & $\mathbf{3 0 - 6 0}$ & $\mathbf{0 - 6 0}$ \\
\hline $\begin{array}{c}\text { A part of the TMCS, spent } \\
\text { for the HMDS formation, \% }\end{array}$ & 70 & 98 & 83 \\
\hline $\begin{array}{c}\text { A part of the TMCS, spent } \\
\text { adsorption, \% }\end{array}$ & 30 & 2 & 17 \\
\hline
\end{tabular}


The data of the material balance calculation show that in the first 30 minutes of silylation, a hydrolysis consumes and transforms into the HMDS $70 \%$ of the reacted TMCS, and $30 \%$ of the last one apparently adsorbs on a calcium hydroxide. The calculation of the material balance for the entire period - up to 60 minutes, has determined that a reaction, making the main contribution to the TMCS conversion increase, is its hydrolysis. Thus, at the first period of the reaction two processes - the TMCS hydrolysis and its adsorption on a calcium hydroxide - take place.

A modified calcium hydroxide, obtained from the reaction mixture at this period, has been investigated. The selected samples of the calcium hydroxide suspension in a nonane have been separated from the filtrate, washed with plenty of dry solvent and dried. Then the samples have been investigated by the methods of the physical and chemical analysis (Xray diffraction, electron microscopy in conjunction with elemental analysis, infrared spectroscopy and thermal analysis).

The X-ray analysis of the sample has showed the presence of a minor amount of calcium hydrooxochloride of a composition of $\mathrm{Ca}(\mathrm{OH})_{2} \cdot \mathrm{CaCl}_{2} \cdot \mathrm{H}_{2} \mathrm{O}$.

The reaction between a TMCS and a calcium hydroxide (due to the TMCS hydrolysis) leads to the formation of the hydrogen chloride which reacts with calcium hydroxide according to the schemes:

$$
\begin{array}{r}
2 \mathrm{HCl}+\mathrm{HO}-\mathrm{Ca}-\mathrm{OH} \rightarrow \mathrm{CaCl}_{2}+2 \mathrm{H}_{2} \mathrm{O} \\
\mathrm{CaCl}_{2}+\mathrm{H}_{2} \mathrm{O}+\mathrm{HO}-\mathrm{Ca}-\mathrm{OH} \rightarrow \mathrm{Ca}(\mathrm{OH})_{2} \cdot \mathrm{CaCl}_{2} \cdot \mathrm{H}_{2} \mathrm{O}
\end{array}
$$

with a calcium chloride and calcium hydrooxochloride formation

As a modified sample contains of chlorides and crystalline hydrates of calcium chloride an interaction between the HMDS and calcium chlorides can't be eliminated. The possible reaction could correspond to the scheme:

$$
\mathrm{Me}_{3} \mathrm{Si}-\mathrm{O}-\mathrm{SiMe}_{3}+\mathrm{CaCl}_{2} \rightarrow \mathrm{Me}_{3} \mathrm{SiCl}+\mathrm{Me}_{3} \mathrm{Si}-\mathrm{O}-\mathrm{CaCl}
$$

A change of the HMDS's concentration in a reaction mixture at a molar ratio of $\mathrm{CaCl}_{2}$ : HMDS $=10: 1$ has been studied by GLC method. The silylation has carried out in a nonane; a calcined calcium chloride containing no water has been applied. In carrying out of the reaction for 14 days, any changes in the content of the HMDS in the reaction mixture are not detected.

The silylation has been carried out also with the watered calcium chloride. The HMDS decline in the reaction mixture at a molar ratio $\mathrm{CaCl}_{2} \cdot \mathrm{nH}_{2} \mathrm{O}: \mathrm{HMDS}=10: 1$ has been investigated by the GLC method, the reaction is carried out in the nonane. The possible reaction could occur according to the scheme:

$$
\mathrm{Me}_{3} \mathrm{Si}-\mathrm{O}-\mathrm{SiMe}_{3}+\mathrm{CaCl}_{2} \cdot \mathrm{nH}_{2} \mathrm{O} \rightarrow \mathrm{Me}_{3} \mathrm{SiOH}+\mathrm{Me}_{3} \mathrm{Si}-\mathrm{O}-\mathrm{CaCl}+\mathrm{n} \mathrm{H}_{2} \mathrm{O}+\mathrm{HCl}
$$

On carrying out of the reaction within 14 days any changes in the content of the HMDS in the reaction mixture are not revealed also.

There are the absorption bands at: $3550 \mathrm{~cm}^{-1}, 1650 \mathrm{~cm}^{-1}, 1280 \mathrm{~cm}^{-1}, 840 \mathrm{~cm}^{-1}$ and 695 $\mathrm{cm}^{-1}$ in the IR spectrum of the modified sample.

The presence of the trimethylsilyl derivatives (- $\mathrm{SiMe}_{3}$ group) in the modified sample is determined by the presence of the absorption bands: $1282-1250 \mathrm{~cm}^{-1}, 841 \mathrm{~cm}^{-1}$ and $756-695$ $\mathrm{cm}^{-1}$ [1]. This spectrum contains absorption bands at $1280 \mathrm{~cm}^{-1}, 840 \mathrm{~cm}^{-1}$ and $695 \mathrm{~cm}^{-1}$, it indicates to the presence of the silylation products in the modified sample.

The electronic microscopy of the modified sample has been carried out in an integrated setting «Comebax» (previously, the sample has been extracted with a toluene for 48 hours under dynamic conditions). The elemental analysis of the particles with a radius greater 
than 3 microns has been carried out with the «electronic probe» method. Sampling has been conducted on 100 particles. The content of silicon has been. It has been determined that the silicon content is $0.19 \%$, which obviously confirms a chemisorption of the trimethylsilyl groups on a calcium hydroxide.

The endothermic heat effects, which correspond to the removal of adsorbed and structural water from the modified sample, can be found with a maximum degree of precision in the DTA thermogram, prescribed for the range 20-500 $0 \mathrm{C}$.

The exothermic heat effect at $388{ }^{\circ} \mathrm{C}$, which may correspond to the destruction of chemisorbed trimethylsilyl groups, is also observed in the DTA curve of this sample. Pascenco [10] has found that the stability limit of the film (on a substrate of a quartz glass) containing trimethylsilyl groups is in the range of $350-550{ }^{\circ} \mathrm{C}$. There is a thermal effect which borders are $310-430{ }^{\circ} \mathrm{C}$, in the DTA curve of the modified sample.

Thus, test data indicate that the silylation realization (under these conditions) leads to the chemisorption of trimethylsilyl groups on a calcium hydroxide. In case of a TMCS, we can speak only about one-point chemisorption

Thus, the analysis data indicate that at this stage of the reaction, we have the following processes:

1. The TMCS hydrolysis by the adsorbed (adsorbed water cannot exclude its participation in the TMCS hydrolysis, but its formation in the reaction, obviously exceeds its consumption) and structural forms of the water contained in the initial $\mathrm{Ca}(\mathrm{OH})_{2}$.

2. The reactions between a hydrogen chloride and $\mathrm{Ca}(\mathrm{OH})_{2}$ with $\mathrm{Ca}(\mathrm{OH})_{2} \cdot \mathrm{CaCl}_{2} \cdot \mathrm{H}_{2} \mathrm{O}$ and $\mathrm{H}_{2} \mathrm{O}$ formation.

3. Equilibrium reactions can lead to the formation of Si-O-Ca- bonds according to the scheme:

$$
\begin{gathered}
\mathrm{Ca}(\mathrm{OH})_{2}+\mathrm{Me}_{3} \mathrm{SiCl} \leftrightarrow \mathrm{Me}_{3} \mathrm{SiOCaOH}+\mathrm{HCl} \\
\left|-\mathrm{CaOH}+\mathrm{Me}_{3} \mathrm{SiCl} \leftrightarrow\right|-\mathrm{CaOSiMe}_{3}+\mathrm{HCl}
\end{gathered}
$$

where $-\mathrm{CaOH}$ is a schematic representation of the partially reacting $\mathrm{Ca}(\mathrm{OH})_{2}$ surface.

The second period of the silylation (from 60 minutes to 180 minutes) is a period corresponding to the possible stage of the «sorption equilibrium». During this time there is a slight change in the TMCS conversion (from 14\% to $17 \%$ ) observed.

Table 2. A material balance of the second period of the silylation

\begin{tabular}{|c|c|c|c|}
\hline Periods, min. & $\mathbf{6 0 - 1 2 0}$ & $\mathbf{1 2 0 - 1 8 0}$ & $\mathbf{6 0 - 1 8 0}$ \\
\hline $\begin{array}{c}\text { A part of the TMCS, spent } \\
\text { for the HMDS formation, } \%\end{array}$ & 100 & $\begin{array}{c}\text { excess } \\
\text { HMDS }\end{array}$ & $\begin{array}{c}\text { excess } \\
\text { HMDS }\end{array}$ \\
\hline $\begin{array}{c}\text { A part of the TMCS, spent } \\
\text { adsorption, } \%\end{array}$ & 0 & 0 & 0 \\
\hline
\end{tabular}

According to the data of the material balance during this period of the silylation a content of HMDS in the reaction mixture exceeds the number that would be formed from the reacted TMCS. Therefore, it has been impossible to eliminate the reactions taking place under the scheme:

$$
\begin{gathered}
(\mathrm{Me})_{3} \mathrm{SiO}-\mathrm{CaOH}+\mathrm{Cl}-\mathrm{Si}(\mathrm{Me})_{3} \rightarrow(\mathrm{Me})_{3} \mathrm{Si}-\mathrm{O}-\mathrm{Si}(\mathrm{Me})_{3}+[\mathrm{HO}-\mathrm{Ca}-\mathrm{Cl}] \\
(\mathrm{Me})_{3} \mathrm{SiO}-\mathrm{Ca}-\mathrm{OH}+\mathrm{Cl}-\mathrm{Si}(\mathrm{Me})_{3} \rightarrow(\mathrm{Me})_{3} \mathrm{SiO}-\mathrm{Ca}-\mathrm{OSi}(\mathrm{Me})_{3}+\mathrm{HCl} \\
(\mathrm{Me})_{3} \mathrm{SiO}-\mathrm{Ca}-\mathrm{OSi}(\mathrm{Me})_{3}+\mathrm{HOH} \rightarrow(\mathrm{Me})_{3} \mathrm{SiO}-\mathrm{CaOH}+(\mathrm{Me})_{3} \mathrm{SiOH} \\
(\mathrm{Me})_{3} \mathrm{SiO}-\mathrm{Ca}-\mathrm{OSsi}(\mathrm{Me})_{3}+\mathrm{HCl} \rightarrow(\mathrm{Me})_{3} \mathrm{SiO}-\mathrm{Ca}-\mathrm{Cl}+(\mathrm{Me})_{3} \mathrm{SiOH}
\end{gathered}
$$




$$
\begin{gathered}
(\mathrm{Me})_{3} \mathrm{SiOH}+\mathrm{HOSi}(\mathrm{Me})_{3} \rightarrow(\mathrm{Me})_{3} \mathrm{SiOSi}(\mathrm{Me})_{3}+\mathrm{H}_{2} \mathrm{O} \\
(\mathrm{Me})_{3} \mathrm{SiO}-\mathrm{Ca}-\mathrm{OH}+\mathrm{HCl} \rightarrow(\mathrm{Me})_{3} \mathrm{SiO}-\mathrm{CaCl}+\mathrm{HOH} \\
(\mathrm{Me})_{3} \mathrm{SiO}-\mathrm{CaCl}+\mathrm{HOH} \rightarrow(\mathrm{Me})_{3} \mathrm{SiOH}+[\mathrm{Cl}-\mathrm{Ca}-\mathrm{OH}]
\end{gathered}
$$

The data of the XR-analysis of the modified sample does not differ from the analysis of the sample selected in the first period.

Comparative analysis of the IR spectrum of the samples of the modified calcium hydroxide, allocated in the first and second periods of the reaction has showed that in the second period of the silylation the absorption bands at $1280 \mathrm{~cm}^{-1}, 810 \mathrm{~cm}^{-1}$ and $695 \mathrm{~cm}^{-1}$, corresponding to the chemisorption of trimethylsilyl groups on a calcium hydroxide, have disappeared from the IR spectrum.

This indicates the prevalence of desilylation and hydrolysis of SiOCa-bonds by the water formed in the reaction mixture at this stage of the silylation process.

$$
\left|-\mathrm{CaOSiMe}_{3}+\mathrm{HOH} \rightarrow\right|-\mathrm{CaOH}+\mathrm{Me}_{3} \mathrm{SiOH}
$$

The electron microscopy of the particles of a mineral sample has showed the presence of only calcium compounds. The elemental analysis realized by the method of electron probe has showed a significant reduction in the silicon content up to $0.014 \%$.

The survey thermogram DTA for the interval $20-500{ }^{\circ} \mathrm{C}$ does not differ from the DTA data given above for the sample selected at the first stage of silylation.

The thermogram DTA of the modified sample contains only endothermic effects at 80 ${ }^{\circ} \mathrm{C}, 200{ }^{\circ} \mathrm{C}$ and $280{ }^{\circ} \mathrm{C}$. The modified sample dehydration starts at $400{ }^{\circ} \mathrm{C}$. The Exothermic heat effect at $388^{\circ} \mathrm{C}$ described for the previous stage is absent on this thermogram.

Thus, the analysis data indicate that at this stage of silylation the following processes take place:

1. The hydrolysis of a trimethylchlorosilane by the structural and adsorbed water contained in the initial $\mathrm{Ca}(\mathrm{OH})_{2}$. At the same time the hydrolysis by the water formed in the reaction mixture begins.

2. The reaction of a hydrolytic cleavage of bonds $\mathrm{Ca}-\mathrm{O}-\mathrm{Si}-\mathrm{Me}_{3}$ including by the water formed in the reaction mixture.

3. The reactions between hydrogen chloride and $\mathrm{Ca}(\mathrm{OH})_{2}$ with a $\mathrm{Ca}(\mathrm{OH})_{2} \cdot \mathrm{CaCl}_{2} \cdot \mathrm{H}_{2} \mathrm{O}$ and a «secondary water» formation.

The third silylation period (from 180 minutes to 300 minutes) is a period possibly corresponding to the stage of a «condensation». There is a new increase in TMCS conversion (from $18 \%$ to $22 \%$ ) at this period.

Table 3. A material balance of the third period of the silylation

\begin{tabular}{|c|c|c|c|}
\hline Periods, min. & $\mathbf{1 8 0 - 2 4 0}$ & $\mathbf{2 4 0 - 3 0 0}$ & $\mathbf{1 8 0 - 3 0 0}$ \\
\hline $\begin{array}{c}\text { A part of the TMCS, spent } \\
\text { for the HMDS formation, \% }\end{array}$ & 72 & 90 & 82 \\
\hline $\begin{array}{c}\text { A part of the TMCS, spent } \\
\text { adsorption, \% }\end{array}$ & 28 & 10 & 18 \\
\hline
\end{tabular}

The data of the mass balance indicate the resumption of TMCS adsorption on a calcium hydroxide at this period of the reaction. This can be explained by the amount of water sufficient for the hydrolysis predominance. However, in the next period of time (240-300 minutes) the proportion of TMCS gone to HMDS formation rises, which can be explained by starting again increase of the amount of water in the reaction system. 
The IR spectrum of the modified sample presents again the absorption bands at 1282 $\mathrm{cm}^{-1}, 840 \mathrm{~cm}^{-1}$ and $695 \mathrm{~cm}^{-1}$, indicating the renewal of trimethylsilyl groups adsorption on a calcium hydroxide (virtually identical to the spectrum obtained for the first period).

The thermogram covers again an exothermic effect at $388{ }^{\circ} \mathrm{C}$, that confirms a resumption of a trimethylchlorosilane chemisorption on a calcium hydroxide in this period.

The elemental analysis also has showed an increase in the silicon content in the light phase to $0.12 \%$, which also confirms the resumption of the trimetilsilinyh groups chemisorption. Consequently, at this stage of the silylation the adsorbed water decreases in the reaction system, due to the continued hydrolysis of TMCS by the water formed in the reaction mixture. But the bound water also increases in the reaction mixture due to the growth of the content of a crystalline calcium hydrooxochloride.

Thus, the analysis data indicate that at this stage of the reaction the following processes take place:

1. A trimethylchlorosilane hydrolysis by the water formed in the reaction mixture and the equilibrium reactions leading to the formation of $\mathrm{Si}-\mathrm{O}-\mathrm{Ca}-$ bonds.

2. Reaction of hydrogen chloride with $\mathrm{Ca}(\mathrm{OH})_{2}$, to the formation of $\mathrm{Ca}(\mathrm{OH})_{2} \cdot \mathrm{CaCl}_{2} \cdot \mathrm{H}_{2} \mathrm{O}$ and $\mathrm{H}_{2} \mathrm{O}$.

Summarizing the research given above, it can be noted that:

The first silylation period is a stage of a rapid achievement of a sorption equilibrium, the main reaction is the TMCS hydrolysis by the adsorbed water contained in the calcium hydroxide. The reaction system accumulates the water. Simultaneously with the TMCS hydrolysis occurs its adsorption on a calcium hydroxide.

The second period of the reaction is a sorption equilibrium stage; the basic processes are TMCS hydrolysis by the water formed in the reaction mixture. Simultaneously in the reaction system occurring cleavage reaction Si-O-Ca- bonds to form excess HMDS.

The third period of reaction is a condensation stage; a calcium hydroxide silylation by the trimethylchlorosilane recommences. An increase of the content of bound water in the composition of a calcium hydroxochloride continues (a thermal effect on the DTA curve at $200{ }^{\circ} \mathrm{C}$ ). Apparently, in the third period of the reaction a repetition of the processes occurring in the first period of the reaction takes place again. The third stage of the process seems to be a renewed stage of «hydrolysis-silylation».

Thus, considering the interaction between a trimethylchlorosilane and a calcium hydroxide, we can speak only about two, to some extent repetitive periods of the reaction. In the first period of the reaction trimethylchlorosilane hydrolysis and condensation prevail and hydrolysis products of hexamethyldisiloxane form. At the same time a trimethylchlorosilane chemisorption is in process. In the second period of the reaction desilylation process dominates, mainly due to the secondary reactions of splitting Si-O-Caties. This leads to an increase in hexamethyldisiloxane's content in the reaction mixture (in comparison with theoretical coolers). It is clear that it can only be a dynamic equilibrium processes, where a content of a hydrogen chloride and a water on the surface of the mineral plays an important role.

\section{References}

1. A.A. Pashhenko, M.G. Voronkov Kremneorganicheskie zashhitnye pokrytija, (Kiev. Tehnika 1969)

2. A.A. Novoselnov, V.I. Sidorov, T.P. Nikiforova, Vestnik MGSU. 1, 160-162 (2007)

3. A.A. Novoselnov, Vestnik MGSU, 4, 181 (2010)

4. A.A. Novoselnov, Vestnik MGSU, 4-3, 133-139 (2011)

5. A. A. Novoselnov Vestnik MGSU, 4, 174 (2011)

6. A. A. Novoselnov A. A. Vestnik MGSU, 7, 114-120 (2013) 
7. A. A. Novoselnov, Mjasoedov E. M. Estestvennye i tehnicheskie nauki, 11-12, 56-57 (2014)

8. A. V. Kiseljova, Jeksperimental'nye metody v adsorbcii i molekuljarnoj hromatografii (Moscow, MGU 1973)

9. Z. Mahachek Z. Sililirovanie $\gamma$-aminopropiltri- jetoksisilanom kal'cinirovannogo kaolina. Himicheskaja promyshlennost', Moscow, p. 10 (1981)

10. A. A. Pashhenko. DSc Thesis Kiev (1984) 